\title{
EVACUATION OF PERSONS FROM SELECTED DEPARTMENTS IN HIGH-RISE BUILDINGS OF HEALTHCARE FACILITIES
}

The article deals with the evacuation of persons from hospital bed wards in high-rise buildings of medical facilities. It presents a proposal for a systems approach and provides a subsequent supportive methodology and tools for planning and implementation of the evacuation of persons with disabilities, which is based on data collection and analysis.

Keywords: Evacuation, evacuation plan, bed wards, patient classification, systematic methodology for evacuation.

\section{Introduction}

The issue of evacuation of persons with disabilities from selected hospital wards presents a multifunctional problem which is significantly extensive and complex. There are actually two groups of patients: walking patients and patients confined to bed who are often in poor physical condition and have psychological problems, which in the event of an emergency evacuation situation requires increased coordination and a higher number of the staff involved. The evacuation itself, and in this respect also the safety of people from the point of time available for their evacuation in general, is still the subject of research [1].

So far no complete methodology, which would serve the medical facilities to develop their evacuation plans for high-rise buildings, has been created in the Czech Republic.

It is necessary to mention that medical facilities due to their typical character of operation create specific positive and negative factors, which have impact on the evacuation of persons [2].

Positive factors are, for example:

- Sufficient space to enable a possible evacuation of persons;

- Constant on-site presence of staff members in facilities enabling to detect danger;

- Constant on-site presence of staff members to be able to carry out the evacuation of persons;

- Possible assistance of staff members from other departments which are not endangered;

- Preparation and training of staff members to be able to handle emergency situations;
- Demanding requirements for construction and operation of medical facilities from the point of view of fire safety and protection of population (legal and technical standards);

- Systematic attention of supervising authorities focused on providing high level safety (e.g. the authority responsible for state fire inspection).

Factors considered as negative are, for example:

- A relatively high concentration of people (especially in multi storey buildings);

- Persons with limited mobility or immobile patients;

- Patients permanently attached to medical devices safeguarding their life functions (e. g. department of anaesthesiology and intensive care (DAIC), intensive care unit (ICU), division of neonatology);

- The necessity to complete some surgical interventions in specialist departments under any situation (e. g. operating rooms);

- Psychological instability of patients having health problems being exposed to sudden unexpected threat [2].

On December 31 2013, there were 188 hospitals with a capacity of 56807 beds (including 47033 acute care beds, 7652 beds in after care and 2122 new-born beds) registered in the Czech Republic [3] - Fig. 1.

\footnotetext{
* ${ }^{1}$ Silvie Benesova, ${ }^{1}$ Isabela Bradacova, ${ }^{2}$ Thomas Jager

${ }^{1}$ Department of Fire Protection, Faculty of Security Engineering, VSB-Technical University, Czech Republic

${ }^{2}$ Munchen, Psytech GmbH, Germany

E-mail: Benesova.Silvie@fnbrno.cz
} 


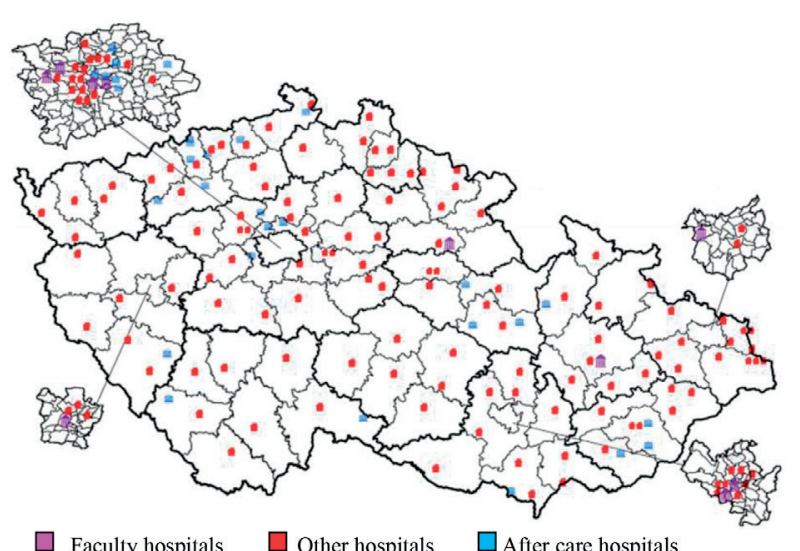

Fig. 1 Hospitals in the Czech Republic (Dec. 31 2013)

\section{Analysis of risks and factors affecting the evacuation of patients from a healthcare facility}

An analysis of risks which might in any way adversely affect either the operation of the healthcare facility or the evacuation process should be done before every planning of evacuation training as well as before creating partial evacuation plans. Regulation of risks is one of the fundamental building blocks of modern management [4].

In our opinion the combination of SWOT analysis and the checklist method is the most suitable to be used in medicine. The reason is that both these methods are relatively simple and easily accessible to the management of a healthcare facility [5].

To evaluate the extent (degree) of risks in the Faculty Hospital Brno (FH Brno), the point semi-quantitative method of risk acceptance was applied, using the formula:

$$
R=P \times Z[4]
$$

where

$\mathbf{R}$ - resultant extent of the risk (the degree of risk acceptance),

$\mathbf{P}$ - probability of the risk occurrence,

$\mathbf{Z}$ - severity of the possible risk consequences.

The results of the dot product of individual risks were processed using a matrix and are shown in the table which served for the evaluation of individual risk acceptances (see Table 1).

Dot product - the acceptance of individual risk types

Table 1

\begin{tabular}{|c|c|}
\hline R/ Risk degree & Risk acceptability \\
\hline $1-2$ & Minimal risk \\
\hline $3-5$ & Low risk \\
\hline $6-8$ & Medium risk \\
\hline $9-14$ & High risk \\
\hline $15-25$ & Very high risk \\
\hline
\end{tabular}

On January 1 2016, the Catalogue of risks of the FH Brno contained 155 risks; the catalogue is constantly updated and extended once in a period of 2 years.

\section{Selected risks associated with the evacuation of persons}

For research purposes the analysis of extent of risks selected from the Catalogue of risks of the FH Brno was conducted. The selected risks might affect the evacuation of persons from the healthcare facility (see Table 2).

A summary of achieved levels of risks associated with the evacuation

Table 2

\begin{tabular}{|c|c|}
\hline Risk type & R / Risk degree \\
\hline Gas explosion & 2.95 \\
\hline Lack of evacuating staff & 2.28 \\
\hline $\begin{array}{l}\text { Risks associated with the operation of } \\
\text { technological systems }\end{array}$ & 0.42 \\
\hline Fire outbreak & 4.19 \\
\hline Toxic chemicals formed by burning & 0.90 \\
\hline $\begin{array}{l}\text { Disruption of organisational operation - energy, } \\
\text { water, gas supply breakdowns }\end{array}$ & 2.30 \\
\hline $\begin{array}{l}\text { Disruption of organisational operation - air- } \\
\text { conditioning problems }\end{array}$ & 1.36 \\
\hline $\begin{array}{l}\text { Disruption of organisational operation - disruption } \\
\text { of medical gas supplies }\end{array}$ & 1.04 \\
\hline $\begin{array}{l}\text { Limited functionality of alternative sources of } \\
\text { electric energy }\end{array}$ & 1.18 \\
\hline Malfunction or breakdown of lifts & 1.25 \\
\hline Flooding & 1.73 \\
\hline Local damage to buildings & 1.31 \\
\hline Disruption of the building statics & 0.61 \\
\hline Contamination of people and material & 0.55 \\
\hline Impassable access paths & 1.03 \\
\hline Suspicious objects (e.g. explosive) & 1.98 \\
\hline Failure of safety systems & 0.82 \\
\hline Explosion - a terrorist attack, collision & 0.86 \\
\hline Panics initiated and spread & 2.13 \\
\hline Helicopter/airplane crashes & 0.50 \\
\hline Impassable escape routes & 1,71 \\
\hline Late announcement of an emergency situation & 1.96 \\
\hline
\end{tabular}




\section{SWOT analysis of patient evacuation in the FH Brno}

Our work experience and risk analyses created in the years 2012 and 2014 enabled us to create the SWOT analysis for patient evacuation in the Faculty Hospital in Brno - Fig. 2.

SWOT analysis is an efficient and simple tool for evaluating the real situation, possible risks, necessary changes and inevitable steps to be taken to transform weak points into strong points and eliminate risks. Simultaneously, it is a tool for long-term planning due to the fact that it comprehensively evaluates the operation of an organisation and helps to detect problems and new growth challenges. It is the method which enables to determine the strong and weak points, opportunities and threats of the organisation [5].

The strengths of the FH Brno are, for example, prior experience of the staff with evacuations, permanent presence of the Emergency dispatching (EMOFF), cooperation with other hospitals in the city of Brno and anti-fire security of the building. Some examples of weaknesses include: the presence of people with impaired mobility, placement of these patients on upper floors, constant high number of people in the building (outpatients, visitors) as well as human factors, such as panic.

Examples of opportunities for the FH Brno are: constant modernisation of the current departments, frequent trainings of evacuation scenarios as well as the preparedness of the medical staff to deal with an emergency situation.

Threats, which the FH Brno is facing, represent possible health and property losses, a high number of visitors in medical facilities, possibility of hidden fire spread, as well as possibility of fire initiation (intentional ignition in the hospital area).

Individual points were evaluated according to the knowledge and information about evacuation plans of the FH Brno. After both the internal and external parts were added together, the sum of 1.5 was obtained, which means that the result achieved using SWOT analysis is highly favourable for the FH Brno.

\begin{tabular}{|c|c|c|c|c|c|c|c|c|}
\hline \multirow{9}{*}{ 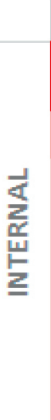 } & \multicolumn{4}{|c|}{ Positive } & \multicolumn{4}{|c|}{ Negative } \\
\hline & \multicolumn{4}{|c|}{ STRENGTHS } & \multicolumn{4}{|c|}{ WEAKNESSES } \\
\hline & & & Importance & Rating & & & Importance & Rating \\
\hline & 1 & Staff experience with evacuation & 0.3 & 4 & 1 & Presence of people with limited mobility (immob & 0.5 & 4 \\
\hline & 2 & Sufficient staffing & 0.1 & 4 & 2 & People with limited mobility are placed upstairs & 0.2 & 2 \\
\hline & 3 & Cooperation with other hospitals & 0.1 & 4 & 3 & Slower evacuation & 0.1 & 1 \\
\hline & 4 & Emergency dispatching & 0.3 & 5 & 4 & Large number of people inside the buildings & 0.1 & 3 \\
\hline & 5 & Building fire protection & 0.2 & 4 & 5 & Panic caused by some patients & 0.1 & 2 \\
\hline & & Total & 4. & & & & 3 & \\
\hline \multirow{8}{*}{ 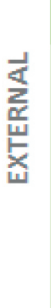 } & \multicolumn{4}{|c|}{ OPPORTUNITIES } & \multicolumn{4}{|c|}{ THREATS } \\
\hline & & & Importance & Rating & & & Importance & Rating \\
\hline & 1 & Hospital modernisation & 0.2 & 3 & 1 & Number of other people in the hospital area & 0.3 & 3 \\
\hline & & Evacuation training & 0.3 & 4 & 2 & Insufficient staffing at night & 0.1 & 3 \\
\hline & 3 & Preparedness of medical staff & 0.3 & 3 & 3 & Hidden spread of fire & 0.2 & 3 \\
\hline & 4 & Building an outside staircase & 0.1 & 1 & 4 & Possibility of setting objects on fire deliberately & 0.3 & 3 \\
\hline & 5 & Grant & 0.1 & 2 & 5 & Possible health and property damages & 0.1 & 1 \\
\hline & & Total & \multicolumn{2}{|c|}{3} & & & \multicolumn{2}{|c|}{2.8} \\
\hline
\end{tabular}

\begin{tabular}{|c|c|c|c|}
\hline SWOT - rating & & TOTAL & 1.5 \\
\hline Strengths & 4.3 & & \\
\hline Weaknesses & 3 & & \\
\hline Total (internal) & 1.3 & & \\
\hline Opportunities & 3 & & \\
\hline Threats & 2.8 & & \\
\hline Total (external) & 0.2 & & \\
\hline
\end{tabular}

Fig. 2 SWOT analysis of patient evacuation in FH Brno 


\section{The evacuation of patients in the event of fire}

In the event of an emergency or catastrophe there may be situations when the evacuation plans need to be activated. If a hospital ward is endangered by fire the situation gets very serious, since the transportation of patients can result in the worsening of their medical conditions or it can even cause their death.

The statistical survey obtained from the software programme ISV 5.0 ("Statistical monitoring of situations") of the General Directorate of Fire Rescue Service of the Czech Republic reports that the major causes fire initiation are:

- Fire,

- Fire manipulation,

- Discarded cigarette butts,

- Disregard of safety regulations,

- Leak of a harmful substance,

- Bomb threats or suspicious objects,

- Dysfunctional infrastructure (power outage, water, gas disruption),

- Technical defects in wiring, machines and equipment,

- Disruption of a building statics,

- Natural disasters.

Fires in buildings of medical facilities are special because of the presence of patients who are unable to move independently, whose mobility is reduced or who are connected to life supporting equipment (electricity, oxygen). Some patients cannot be moved with their beds, their medical conditions can possibly be worsened, others have the lower ability to react and lower self-control which can lead to their panic reactions.

\section{Analysis of preparedness of the faculty hospitals in the Czech Republic for emergency evacuations}

The evacuation of persons from the premises of medical facilities represents a serious problem in the event of emergency. The character of this issue is complicated also due to variability of types of people present in the hospitals at the time of evacuation. These can be outpatients, hospitalised patients or random visitors. The core of the problem is the fact that any manipulation or transport of immobile patients can lead to the worsening of their health conditions or even to their death.

In order to avoid negative effects of emergency evacuations of patients in hospitals or at least to eliminate their adverse consequences, all the hospitals should have the scheme containing following points:

- Pre-planned emergency evacuation scheme;

- Unambiguous marking of escape routes in the buildings (regular inspections);

- Establishment of a crisis committee or centre;
- Introduction of registration and classification (sorting) of patients;

- Ways of safeguarding medical records;

- Assigning of persons responsible for activation of evacuation plans in the departments;

- Evacuation workflow for an intensive care unit (ICU) and department of anaesthesiology and intensive care (DAIC) - (order of patient and equipment evacuation);

- Consultation of the prepared plan with the fire brigade (responsibility, coordination);

- Means of transport and technical provision (face masks, special mattresses, evacuation mats, etc.).

To monitor and analyse the state of preparedness of the Czech hospitals for emergency evacuations, we developed Checklists which were sent to 14 biggest hospitals (mostly faculty hospitals) in the Czech Republic. From the 14 addressed hospitals only one hospital rejected to participate and so the return of checklists represented $92.85 \%$.

In the first phase we wanted to know to which category (in compliance with the Fire Safety of Building Regulations in the Czech Republic) the addressed hospitals belong. We further wanted to know which parts their high-rise buildings consist of (outpatient departments, hospital wards and bed complements), how often they train evacuation scenarios and how long the evacuation of the ward block with the highest number of immobile patients would last (see Fig. 3).

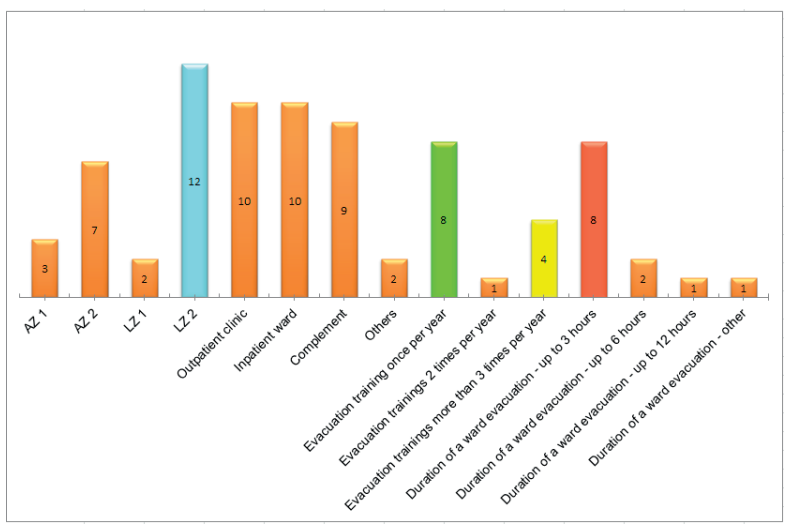

AZ 1- outpatient clinic - maximally 3 offices, AZ 2 - outpatient clinic more than 3 offices, LZ 1 -small hospital without bed wards, LZ 2 - hospital with 1 or more bed wards

Fig. 3 The $1^{\text {st }}$-graphical illustration of the number of hospitals included in the given category of questions

The graph shows that from the total number of 13 hospitals participating in the survey:

- 12 hospitals belong to the LZ 2 group (hospitals with 1 or more bed wards), 
- 8 hospitals undergo evacuation drills at least once per year,

- 4 hospitals undergo evacuation drills at least 3 times per year,

- 8 hospitals would evacuate the wards with a maximum number of immobile patients within 3 hours.

In the second phase, the questions related to the creation of evacuation plans, existence of the map of risks, the mapping of staffing and number immobile patients on the wards and number of devices to assist for transportation of immobile patients, were processed. Answers are shown in the graph (see Fig. 4).

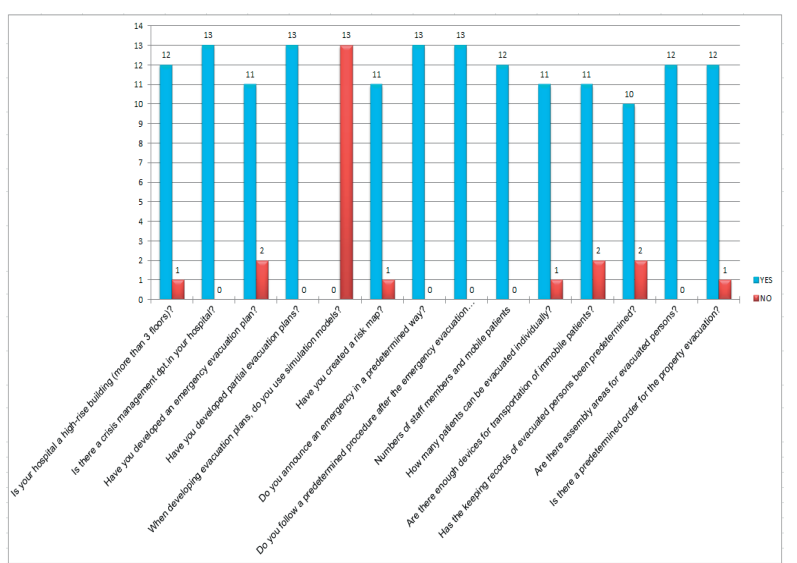

Fig. 4 The $2^{\text {nd }}$ phase - graphical illustration of the number of hospitals included in the given category of questions

The graph shows that from the total number of 13 hospitals participating in the surveys:

- 12 hospitals have a high-rise building with more than 3 floors,

- 13 hospitals have developed partial evacuation plans,

- 11 hospitals have elaborated the risks (the methods for risk evaluation differ),

- 13 hospitals did not use software simulation models when designing their evacuation plans,

- 10 hospitals have a predetermined way of labelling and registration of evacuated people,

- 2 hospitals have not sufficient devices to assist for transportation of immobile patients and have no predetermined way of their labelling and registration.

We can see that none of the 13 surveyed hospitals used software simulation models for development of their emergency evacuation plans. Instead, they use software AutoCad (software for $2 \mathrm{D}$ and $3 \mathrm{D}$ design and construction of the Co. Autodesk) within pasportisation of hospitals.

From the analysis of answers related to problems occurring during emergency evacuation training we can see that the hospital faced following problems during evacuation drills:

- Inaccessibility of the evacuation means of transport;

- Passing on information to fire and rescue service members;
- Decreased audibility when telephoning during the evacuation broadcast;

- Lack of evacuation lifts (old-fashioned hospital building);

- Impassability of the access roads to buildings, late activation of fire safety devices;

- Responsibility for children patients (up to 19 years) - permanent supervision

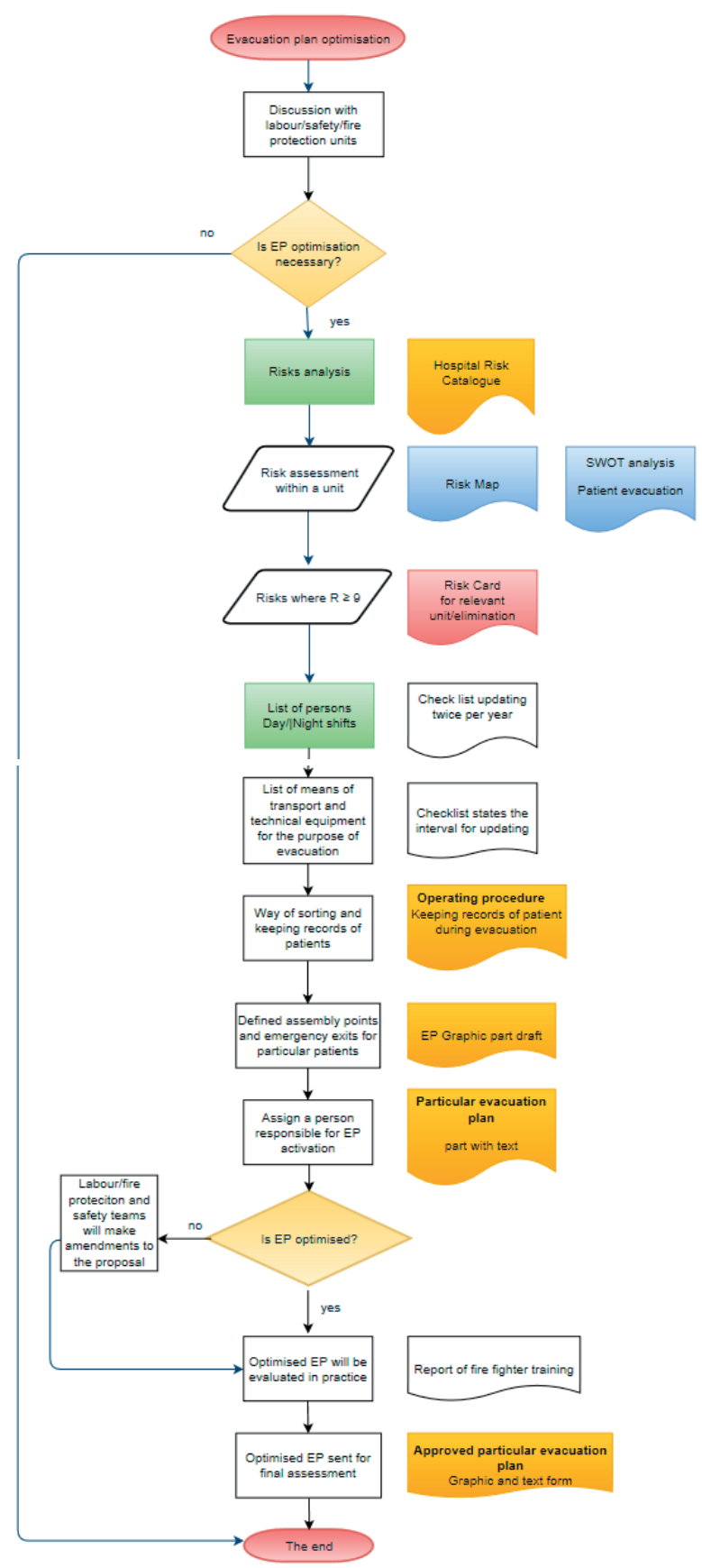

Fig. 5 Flow diagram of the evacuation plan optimisation 
- Difficult evacuation of children - incubators in the neonatal units;

- Unwillingness of the staff to participate in the evacuation drills ("Why?")

- The clinic management role versus staff members during the initial phase of an emergency evacuation;

- Technical character (bed widths, lifts, etc.).

\section{Flow diagram of the methodological progress for the evacuation plan optimisation}

Before anyone begins either to develop an emergency evacuation plan or to optimise the existing one, the first step to do should be to make an analysis and control of risks and their evaluation. The objective of this article was to contribute to the issue of evacuation of persons from selected departments located in high-rise buildings in health care facilities and to design a model (of a flow diagram) and consequent methodology (principles) for creation of partial evacuation plans or for optimisation of existing evacuation plans.

The acquired data enabled us to formulate the steps which should precede the development of partial plans or their optimisation.

Figure 5 illustrates the flow diagram of the whole methodological process designed for those involved in development of evacuation plans.

\section{Conclusion}

With the help of the abovementioned methods and analyses we obtained data and results which confirmed the introductory hypothesis saying that in order to avoid negative impacts on patients evacuated from hospitals or at least eliminate the effects of emergency evacuation, the hospitals should complete the following steps:

1. Tocreate a catalogue of risks (focus on the risks which could cause or influence the evacuation);

2. To carry out a survey of the departments with a higher probability of risks which might result in emergency evacuation initiation;

3. To make lists of people (patients and staff members) present on average in day and night shifts;

4. To decide on how to register and sort the patients;

5. To assign people responsible for the evacuation plan activation in departments;

6. To determine assembly locations and deviation tracks for specific categories of patients;

7. Workflows for activation of "partial" evacuation plans of a particular clinic;

8. Workflows for evacuation of UIC/DAIC (the order of patient transportation);

9. To decide on how to secure the medical documentation.

10. To make a list of means of transport and technical equipment for emergency evacuation;

11. To make regular inspections of exit routes labelling;

12. To organise fire fighting training courses (functional verification of optimised evacuation plans);

13. To provide the training of staff members on the evacuation course.

The methodology proposed in this article is based on a thorough theoretical background, but it also enables to perform more sophisticated preparation in a simpler way and to execute a demanding evacuation in a complicated environment of medical facilities.

\section{References}

[1] MOZER, V., POKORNY, J., KUCERA, P., VRABLOVA, L., WILKINSON, P.: Utility of Computer Modelling in Determination of Safe Available Evacuation Time. Communications - Scientific Letters of the University of Zilina, vol. 17, No. 1, 2015, pp. 67-72, ISSN 1335-4205.

[2] FOLWARCZNY, L., POKORNY, J.: Evacuation of Persons in Health Care Facilities, $1^{\text {st }}$ ed. (in Czech), [online], p. 13, [cit. $2015-04$ 17], Ostrava : The Association for Fire and Safety Engineering, 2006. ISBN 80-86634-92-2. Available from: http://www.unbr. cz/ Data/files/Konf\%20MeKa07/III3_folwarczny.pdf

[3] TYPLTOVA, J.: Hospitals in the Czech Republic in the Year 2013, Ustav zdravotnickych informaci a statistiky CR, [online], 2014 [cit. 2016-03-17]. Available from: http://www. uzis.cz/rychle-informace/nemocnice-ceske-republice-roce-2013\#_ftn4.

[4] SKRLA, P., SKRLOVA, M.: Regulation of Risks in Healthcare Facilities, $1^{\text {st }}$ ed., Prague : Grada Publishing, 2008, ISBN 978-80-2472616-81.

[5] SMEJKAL, V., RAIS, K.: Regulation of Risks in Companies and other Organisations, $4^{\text {th }}$ updated and extended edition, Prague : Grada, 2013, Expert, ISBN 978-80-247-4644-9. 